\title{
Liquid Chromatography-Tandem Mass Spectrometry Methods for Determination of Delamanid in Mouse Plasma and Lung
}

\author{
Yukihiro Hirao*, Toshihisa Koga, Noriyuki Koyama, Yoshihiko Shimokawa, \\ Ken Umehara \\ Tokushima Research Institute, Otsuka Pharmaceutical Co., Ltd., Tokushima-shi, Japan \\ Email: *Hirao.Yukihiro@otsuka.jp
}

Received 12 December 2014; accepted 9 January 2015; published 16 January 2015

Copyright (C) 2015 by authors and Scientific Research Publishing Inc.

This work is licensed under the Creative Commons Attribution International License (CC BY). http://creativecommons.org/licenses/by/4.0/

(c) (i) Open Access

\begin{abstract}
Sensitive and selective liquid chromatography-tandem mass spectrometry methods have been developed and validated for the determination of delamanid in mouse plasma and lung. Sample preparation involved liquid-liquid extraction with diethyl ether for plasma, or protein precipitation followed by liquid-liquid extraction with tert-butyl methyl ether for lung homogenate. Chromatographic separation was performed on a reversed phase column with a linear gradient elution using purified water-formic acid (1000:2, v/v) and methanol-formic acid (1000:2, v/v) at a flow rate of $0.2 \mathrm{~mL} / \mathrm{min}$. Detection was performed on a triple-quadrupole tandem mass spectrometer using positive ion electrospray ionization in the selected reaction monitoring mode. The analytical methods were successfully validated for selectivity, calibration curve, accuracy, precision, extraction recovery, and stability over a range of $6-1000 \mathrm{ng} / \mathrm{mL}$ for plasma and $10-1000 \mathrm{ng} / \mathrm{mL}$ for lung homogenate. The validated methods were successfully applied for evaluation of pharmacokinetics of delamanid in male mice.
\end{abstract}

\section{Keywords}

Delamanid, LC-MS/MS, Mouse Plasma, Mouse Lung, Pharmacokinetics

\section{Introduction}

Delamanid (OPC-67683), (R)-2-methyl-6-nitro-2-[(4-\{4-[4-(trifluoromethoxy)phenoxy]piperidin-1-yl\}phenoxy) methyl]-2,3-dihydroimidazo[2,1-b]oxazole, is a new antituberculosis agent derived from the nitro-dihydro-im-

\footnotetext{
${ }^{*}$ Corresponding author.
}

How to cite this paper: Hirao, Y., Koga, T., Koyama, N., Shimokawa, Y. and Umehara, K. (2015) Liquid ChromatographyTandem Mass Spectrometry Methods for Determination of Delamanid in Mouse Plasma and Lung. American Journal of Analytical Chemistry, 6, 98-105. http://dx.doi.org/10.4236/ajac.2015.62009 
idazooxazole class of compounds and inhibits mycolic acid synthesis [1]-[3]. Delamanid has been approved as a new drug for the treatment of MDR-TB and launched onto the market in Europe and Japan. The pharmacodynamic profiles of delamanid were investigated using in vitro and in vivo mouse models, and delamanid showed highly effective therapeutic activity at low doses in vivo [4]. To examine the preclinical plasma pharmacokinetics and distribution of delamanid to the lung, the target organ for tuberculosis treatment, a sensitive, selective and highly reproducible analytical method is necessary. To the best of our knowledge, there is no validated method currently reported in literature for the quantification of delamanid in biological samples. This paper reports on sensitive and validated LC-MS/MS methods for the determination of delamanid in mouse plasma and lung. The methods were successfully applied to a pharmacokinetic study of delamanid after oral administration in male mice.

\section{Experimental}

\subsection{Chemicals and Reagents}

Delamanid and the internal standard (IS, OPC-51803) were supplied by Otsuka Pharmaceutical Co., Ltd. These chemicals structures are shown in Figure 1. Methanol and acetonitrile (high performance liquid chromatography [HPLC] grade) were purchased from Merck Ltd., Japan (Tokyo, Japan) and Fisher Scientific Inc. (Kanagawa, Japan), respectively. Diethyl ether and tert-butyl methyl ether (residual pesticide analysis grade), and formic acid (special grade) were purchased from Sigma-Aldrich Japan, K.K. (Tokyo, Japan). Carbonate buffer (0.5 mol/L, $\mathrm{pH} 10)$ and phosphate buffer ( $0.067 \mathrm{~mol} / \mathrm{L}, \mathrm{pH} 7)$ were purchased from Nacalai Tesque, Inc. (Kyoto, Japan). Physiological saline was purchased from Otsuka Pharmaceutical Factory, Inc. (Tokushima, Japan). Water was purified using Milli-Q water purification system (Millipore Corp., Billerica, MA, USA).

\subsection{Instrumentation and Analytical Conditions}

For plasma analysis, the Shimadzu HPLC system consisted of two LC-10AD pumps, a SIL-10AXL autosampler with sample cooler S, a CTO-10AC column oven, and a DGU-14A degasser (Shimadzu Corp., Kyoto, Japan). For lung analysis, the Shiseido HPLC system consisted of two Model 3001 pumps, a Model 3023 autosampler, a Model 3004 column oven, and a Model DG-1310 degasser (Shiseido Co., Ltd., Tokyo, Japan). Separation of delamanid and IS was achieved with a Capcell Pak C18 MG column $(50 \mathrm{~mm} \times 2.0 \mathrm{~mm}, 3 \mu \mathrm{m}$, Shiseido Co., Ltd.), held at $25^{\circ} \mathrm{C}$ for plasma or $40^{\circ} \mathrm{C}$ for lung analysis. The mobile phase used for chromatographic separation were purified water-formic acid (1000:2, v/v) (Solvent A) and methanol-formic acid (1000:2, v/v) (Solvent B). The HPLC system was set up to operate at a flow rate of $0.2 \mathrm{~mL} / \mathrm{min}$ under the linear gradient conditions as in Table 1 . The autosampler tray was maintained at $4^{\circ} \mathrm{C}$.

The HPLC eluate was introduced directly into a triple-quadrupole mass spectrometer, TSQ7000 (Thermo Electron Corp., San Jose, CA, USA) for plasma analysis or API3000 (Applied Biosystems/MDS SCIEX, Ontario, Canada) for lung analysis, equipped with electrospray ionization (ESI) source. The mass spectrometer was operated in the positive ESI selected reaction monitoring (SRM) mode. The SRM transitions, including their associated parameters, are shown in Table 2. Data acquisition and processing were performed using Xcalibur software version 1.2 (Thermo Electron Corp.) or Analyst software version 1.1 (Applied Biosystems/MDS SCIEX).

\subsection{Preparation of Calibration Standard and Quality Control Samples}

Delamanid was dissolved in methanol $(500 \mu \mathrm{g} / \mathrm{mL}$, stock solution) and then diluted with methanol to prepare working solutions with concentration ranging from 0.06 to $10 \mu \mathrm{g} / \mathrm{mL}$ for plasma analysis, or 0.1 to $10 \mu \mathrm{g} / \mathrm{mL}$ for lung analysis. The IS was dissolved in methanol $(100 \mu \mathrm{g} / \mathrm{mL}$, stock solution) and then diluted with methanol to prepare the IS solution at $2 \mu \mathrm{g} / \mathrm{mL}$ for plasma analysis or $1 \mu \mathrm{g} / \mathrm{mL}$ for lung analysis. All stock solutions were stored in the dark at $4^{\circ} \mathrm{C}$. Calibration standard and quality control (QC) samples were prepared by spiking $10 \mu \mathrm{L}$ of the working solutions to $0.1 \mathrm{~mL}$ of each blank matrix under ice-cold condition. The calibration standard samples comprised six concentrations (6, 20,60, 200, 600, and $1000 \mathrm{ng} / \mathrm{mL}$ for plasma; 10, 30, 100, 300, 800, and $1000 \mathrm{ng} / \mathrm{mL}$ for lung homogenate). QC samples were prepared at three concentration levels (16, 160, and 800 $\mathrm{ng} / \mathrm{mL}$ for plasma; 30, 100, and $800 \mathrm{ng} / \mathrm{mL}$ for lung homogenate). For each analytical run, calibration standard and QC samples were freshly prepared. 


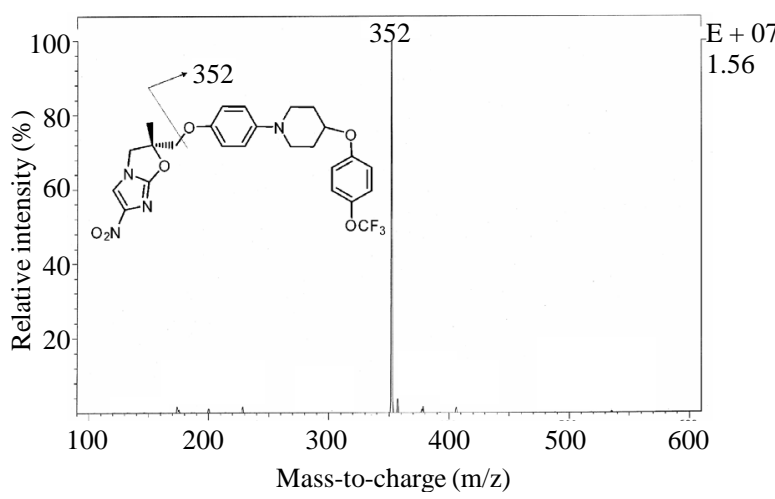

(a)

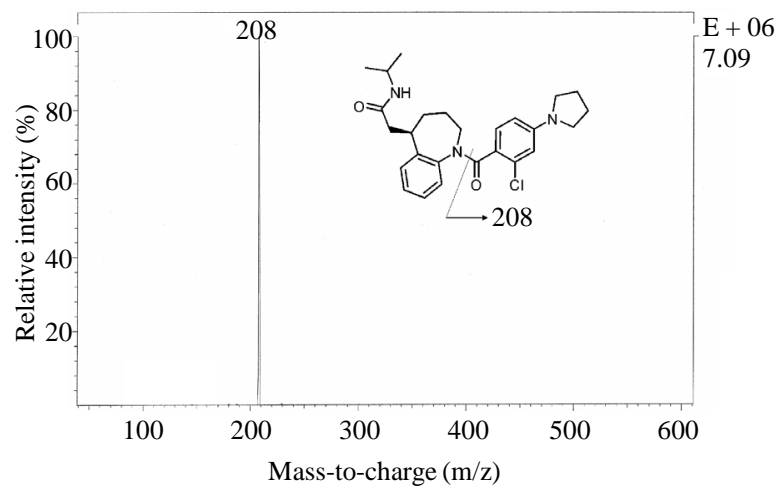

(b)

Figure 1. Product ion spectra and chemical structures of delamanid (a) and internal standard OPC-51803 (b).

Table 1. Gradient program for the separation of delamanid and IS.

\begin{tabular}{ccccc}
\hline Matrix & Time (min) & Solvent A (\%) & Solvent B (\%) & Flow rate (mL/min) \\
\hline \multirow{3}{*}{ Plasma } & Initial & 50 & 50 & 0.2 \\
& 3.00 & 10 & 90 & 0.2 \\
& 6.00 & 10 & 90 & 0.2 \\
& 6.01 & 50 & 50 & 0.2 \\
\hline \multirow{3}{*}{ Lung homogenate } & 12.00 & 50 & 50 & 0.2 \\
& Initial & 70 & 30 & 0.2 \\
& 3.00 & 10 & 90 & 0.2 \\
\hline
\end{tabular}

Linear gradient.

Table 2. SRM transitions for delamanid and IS and mass spectrometer conditions.

\begin{tabular}{|c|c|c|c|c|c|c|}
\hline Matrix & Time (min) & Compound & Precursor ion $(\mathrm{m} / \mathrm{z})$ & Product ion $(m / z)$ & Scan time (sec) & Collision energy $(\mathrm{eV})$ \\
\hline \multirow{4}{*}{ Plasma } & $0-4.1$ & & & & & \\
\hline & & Delamanid & 535 & 352 & 0.5 & 30 \\
\hline & $4.1-6.0$ & & & & & \\
\hline & & IS & 454 & 208 & 0.5 & 30 \\
\hline
\end{tabular}

Spray voltage $4.5 \mathrm{kV}$; electron multiplier voltage $1.5 \mathrm{kV}$; nitrogen sheath gas pressure 70 psi; nitrogen auxiliary gas pressure 10 (arbitrary units); argon collision gas pressure $2.0 \mathrm{~m}$ Torr; capillary temperature $240^{\circ} \mathrm{C}$.

\begin{tabular}{|c|c|c|c|c|c|}
\hline \multicolumn{3}{|c|}{$0-7.5$} & \multicolumn{3}{|c|}{ (cycle scan) } \\
\hline $\begin{array}{c}\text { Lung } \\
\text { homogenate }\end{array}$ & Delamanid & 535 & 352 & 0.3 & 33 \\
\hline & IS & 454 & 208 & 0.3 & 27 \\
\hline
\end{tabular}

Spray voltage $4.5 \mathrm{kV}$; electron multiplier voltage $2.5 \mathrm{kV}$; nitrogen nebulizer gas 14 (arbitrary units); nitrogen curtain gas 6 (arbitrary units); nitrogen collision gas 12 (arbitrary units); heated gas pressure $70 \mathrm{psi}$; heated gasflow rate $7 \mathrm{~L} / \mathrm{min}$; heated gas temperature $475^{\circ} \mathrm{C}$.

\subsection{Sample Preparation}

Plasma: To $0.1 \mathrm{~mL}$ of plasma sample, $10 \mu \mathrm{L}$ of IS solution, $0.5 \mathrm{~mL}$ of carbonate buffer, and $5 \mathrm{~mL}$ of diethyl ether were added under ice-cold condition. After shaking for 10 minutes, the mixture was centrifuged at $1800 \times \mathrm{g}$ for 10 minutes. The organic layer was transferred into another test tube and evaporated to dryness under a stream of nitrogen at $40^{\circ} \mathrm{C}$. The residue was dissolved in $0.2 \mathrm{~mL}$ of methanol-purified water-formic acid (50:50:1, v/v/v) 
by sonication, and the resulting solution was centrifuged at 16,000 $\times$ g for 5 minutes. The supernatant was transferred to an autosampler vial and a $10 \mu \mathrm{L}$-aliquot was injected into the LC-MS/MS system.

Lung: The lungs were homogenized in nine volumes of physiological saline using a Polytron homogenizer (Kinematica AG, Lucerne, Switzerland). To $0.1 \mathrm{~mL}$ of lung homogenate sample, $10 \mu \mathrm{L}$ of IS solution, and 0.1 $\mathrm{mL}$ of acetonitrile were added under ice-cold condition and mixed. The mixture was centrifuged at $12,000 \times \mathrm{g}$ at $4^{\circ} \mathrm{C}$ for 5 minutes. To $0.1 \mathrm{~mL}$ of the supernatant, $1 \mathrm{~mL}$ of phosphate buffer, and $5 \mathrm{~mL}$ of tert-butyl methyl ether were added. After shaking for 10 minutes, the mixture was centrifuged at $1800 \times \mathrm{g}$ for 10 minutes. The organic layer was transferred into another test tube and evaporated to dryness under a stream of nitrogen at $40^{\circ} \mathrm{C}$. The residue was dissolved in $0.2 \mathrm{~mL}$ of methanol-purified water-formic acid (900:100:2, v/v/v) by sonication, and the resulting solution was transferred to an autosampler vial and a $5 \mu \mathrm{L}$-aliquot was injected into the LC-MS/MS system.

\subsection{Method Validation}

\subsubsection{Selectivity}

The selectivity of the analytical methods was evaluated by comparing the chromatograms of six different batches of each blank matrix with the spiked matrices at the lower limit of quantification (LLOQ) level. The peak area of an interfering peak should not exceed $20 \%$ of the LLOQ for delamanid and $5 \%$ for the IS.

\subsubsection{Calibration Curve and LLOQ}

Calibration curves were constructed by analyzing calibration standard samples at six concentrations of delamanid ranging 6 - $1000 \mathrm{ng} / \mathrm{mL}$ for plasma and $10-1000 \mathrm{ng} / \mathrm{mL}$ for lung homogenate. The quadratic regression equation $\left(y=a x^{2}+b x+c\right)$ with $1 / x$ weighting was calculated by the least square method using the peak-area ratios of delamanid to IS $(y)$ and the spiked concentrations of delamanid $(x)$. The calibration curves were evaluated by the determination coefficients $\left(r^{2}\right)$ or correlation coefficients $(r)$, and the relative error (RE) of the back-calculated concentrations for each calibration level. The LLOQ was defined as the lowest concentration on the calibration curve with RE of the calculated concentration within $\pm 20 \%$ and the coefficient of variation (CV) within $20 \%$ by analyzing six LLOQ samples prepared from six different matrix batches.

\subsubsection{Accuracy and Precision}

The accuracy and precision of the analytical methods were evaluated by analyzing five replicates of QC samples at three concentration levels on the same day and on three consecutive days for intra- and inter-day accuracy and precision, respectively. Accuracy was expressed as RE of the calculated concentrations, and precision was expressed as CV. To be acceptable, intra- and inter-day accuracy should be within $\pm 15 \%$, and intra- and inter-day precision should be within $15 \%$.

\subsubsection{Extraction Recovery}

The extraction recovery rates of delamanid and IS were evaluated at three concentration levels of delamanid and one concentration level of the IS with three replicates by comparing the peak area responses of the compounds obtained from each matrix spiked before extraction with those spiked after extraction.

\subsubsection{Stability}

The stability of delamanid and IS in each stock solution was evaluated at $4{ }^{\circ} \mathrm{C}$ in the dark for 12 weeks and 7 weeks, respectively. The stability of delamanid in mouse plasma and lung homogenate was evaluated at low and high concentration levels (16 and $800 \mathrm{ng} / \mathrm{mL}$ for plasma, 30 and $800 \mathrm{ng} / \mathrm{mL}$ for lung homogenate) with three replicates. The stability of delamanid was tested under the following conditions: 1 ) freeze-thaw stability after two or three cycles at $-20^{\circ} \mathrm{C}$; 2) short-term stability under ice-cold condition for 2 hours; 3) long-term stability at $-20^{\circ} \mathrm{C}$ for 4 weeks, 6 weeks, or 9 weeks; 4) post-preparative stability in the autosampler maintained at $4^{\circ} \mathrm{C}$ for 24 hours.

\subsection{Application to a Pharmacokinetic Study}

Thirty male ICR mice (age: 6 - 7 weeks, body weight: 33.9 - 40.8 g) were purchased from Japan SLC Inc., and were kept in environmentally controlled quarters (temperature: $22^{\circ} \mathrm{C}-24^{\circ} \mathrm{C}$, relative humidity: $55 \%-63 \%$, 
light/dark cycle: 12 hours) for 12 - 13 days before the experiment began. Non-fasted animals were used for the experiment. Animal experiments were carried out in accordance with the Institutional Guidelines for Animal Care and Use.

Heparinized blood and lung samples were collected at 0.5, 1, 2, 4, 6, 8, 12, 24, 32, and 48 hours after a single oral administration of delamanid at a dose of $3 \mathrm{mg} / \mathrm{kg}$ to male mice. Plasma was obtained by centrifugation of blood at $1800 \times \mathrm{g}$ for 10 minutes at $4^{\circ} \mathrm{C}$. The lung sample was prepared by homogenizing immediately in nine volumes of physiological saline. The plasma and lung homogenate samples were stored at $-20^{\circ} \mathrm{C}$ until analysis. The lung concentrations of delamanid were calculated by multiplying the lung homogenate concentrations by a factor of 10. The pharmacokinetic parameters, peak concentration $\left(\mathrm{C}_{\max }\right)$, time to peak concentration $\left(\mathrm{t}_{\max }\right)$, area under the concentration-time curve calculated to the last observable concentration at time $t\left(A_{U} C_{t}\right)$, area under the concentration-time curve from time zero to infinity $\left(\mathrm{AUC}_{\infty}\right)$, and apparent elimination half-life $\left(\mathrm{t}_{1 / 2}\right)$ were calculated based on the average concentration of delamanid in plasma and lung by non-compartmental analysis using WinNonlin Standard (Version 4.0.1, Pharsight Co., CA, USA).

\section{Results and Discussion}

\subsection{Method Development}

For the selection of IS, several compounds were tested, and OPC-51803 was ultimately selected in consideration of its suitable retention time, high extraction recovery, and similar mass spectrometric behavior to the analyte. For the optimization of chromatographic conditions, several C18 columns were compared on the basis of the sensitivity, peak shape, separation from some probable metabolites, and retention times. As a result, Shiseido Capcell Pak C18 MG column $(50 \mathrm{~mm} \times 2.0 \mathrm{~mm}, 3 \mu \mathrm{m})$ column was chosen to determine delamanid in plasma and lung homogenate. For the optimization of mass spectrometry conditions, both positive and negative ionization modes were tested. It was observed that the intensities of delamanid and IS in positive mode were much greater than those in negative mode, and the most predominant ions were protonated molecular ion $[\mathrm{M}+\mathrm{H}]^{+}$at $\mathrm{m} / \mathrm{z} 535$ and 454, respectively. The product ion spectra by MS/MS collision-induced dissociation of the massselected precursor ion of each compound are shown in Figure 1. The most intense fragment peak of each MS/MS spectrum was selected as the monitor ion. The other parameters were optimized to obtain the highest intensity for the analyte. As for the sample preparation, a liquid-liquid extraction method with diethyl ether was chosen for plasma analysis in consideration of its minimal interference with endogenous substances and its high extraction recovery. On the other hand, for lung homogenate analysis, the protein precipitation followed by liquid-liquid extraction with tert-butyl methyl ether was chosen to improve the extraction recovery.

\subsection{Selectivity}

The typical chromatograms of the blank matrices and the spiked matrices with delamanid at the LLOQ level and IS are shown in Figure 2(A) and Figure 2(B). There were no interfering peaks at the retention times of delamanid and IS.

\subsection{Calibration Curve}

The typical quadratic regression equations for the calibration curves were as follows: plasma, $y=-0.000000104 x^{2}$ $+0.00644 x+0.00444$; lung homogenate, $y=0.0000000878 x^{2}+0.00330 x+0.00169$. For plasma, the determination coefficients $\left(r^{2}\right)$ were 0.9968 or better $(n=10)$, and for lung, the correlation coefficients $(r)$ were 0.9994 or better $(n=13)$, which showed a good correlation in both matrices. And, the RE of the back-calculated concentrations were within $\pm 15 \%$ ( $\pm 20 \%$ for LLOQ) for at least five out of six standard samples (including LLOQ and upper limit of quantification).

\subsection{LLOQ}

The accuracy and precision in the LLOQ sample for plasma were $-15.2 \%$ and $5.2 \%$, respectively, and those for lung homogenate were $-1.7 \%$ and $4.1 \%$, respectively. The LLOQ of the analytical methods in mouse plasma and lung homogenate were determined to be 6 and $10 \mathrm{ng} / \mathrm{mL}$, respectively. 
(a)

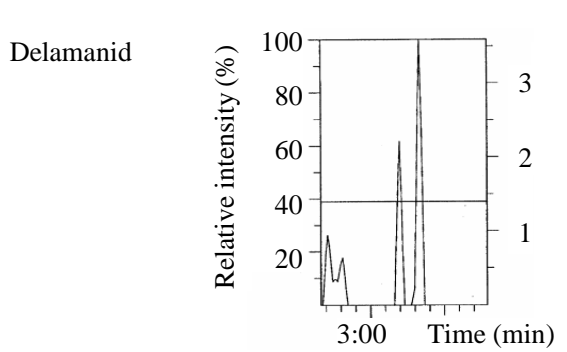

IS

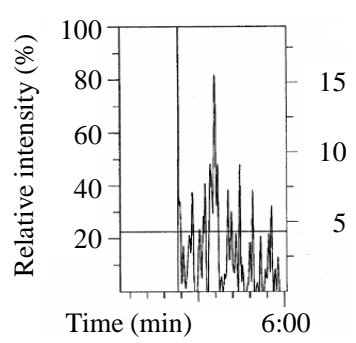

(A) (b)
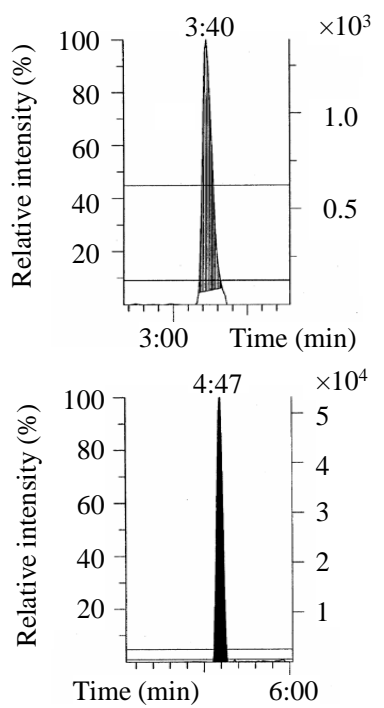
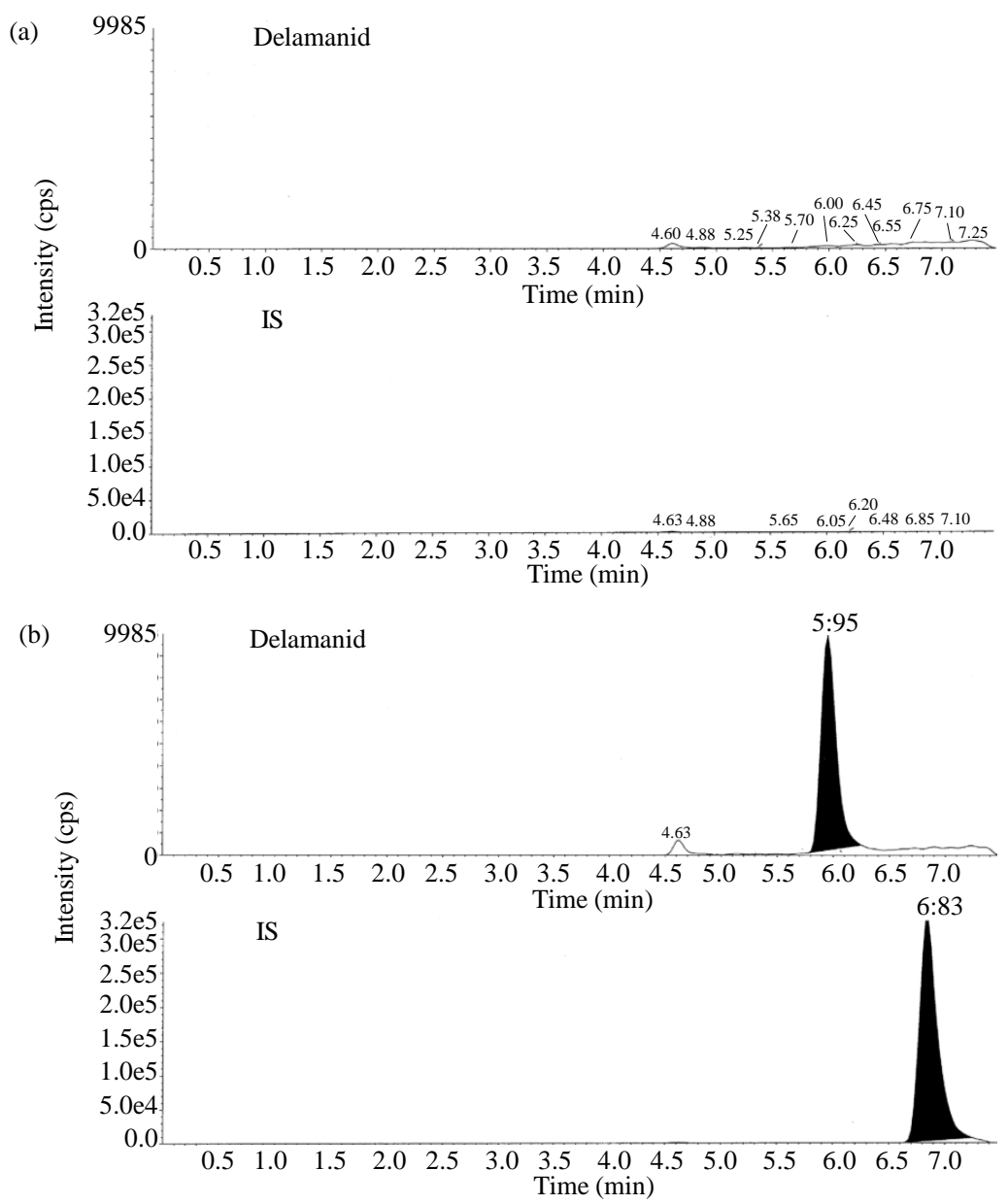

(B)

Figure 2. (A) LC-MS/MS chromatograms of blank plasma (a) and spiked plasma (b) with delamanid at the LLOQ level and IS; (B) LC-MS/MS chromatograms of blank lung homogenate (a) and spiked lung homogenate (b) with delamanid at the LLOQ level and IS. 


\subsection{Accuracy, Precision, and Extraction Recovery}

The accuracy, precision, and extraction recovery data are summarized in Table 3. For both matrices, the accuracy and precision for intra-day and inter-day assays were within the criteria of the validation. The extraction recovery rates of delamanid from both matrices were not less than $90.8 \%$, and those of IS were not less than $99.3 \%$.

\subsection{Stability}

In each stock solution at $4^{\circ} \mathrm{C}$, delamanid and IS were found to be stable for 12 weeks and 7 weeks, respectively. Stability results in biological matrices are summarized in Table 4. In plasma, delamanid was found to be stable after 3 freeze-thaw cycles at $-20^{\circ} \mathrm{C}$, for 2 hours under ice-cold condition, for 9 weeks at $-20^{\circ} \mathrm{C}$, and for 24 hours in processed samples at $4^{\circ} \mathrm{C}$. In lung homogenate, delamanid was found to be stable after 2 freeze-thaw cycles at $-20^{\circ} \mathrm{C}$, for 2 hours under ice-cold condition, for 4 weeks at $-20^{\circ} \mathrm{C}$, and for 24 hours in processed samples at $4^{\circ} \mathrm{C}$, but unstable after 3 freeze-thaw cycles at $-20^{\circ} \mathrm{C}$ and for 6 weeks at $-20^{\circ} \mathrm{C}$.

\subsection{Application to a Pharmacokinetic Study}

The validated methods were applied to the analysis of plasma and lung samples obtained from male mice after a single oral administration of delamanid at a dose of $3 \mathrm{mg} / \mathrm{kg}$. The mean plasma and lung concentration-time profiles of delamanid are shown in Figure 3, and the pharmacokinetic parameters are summarized in Table 5. The $\mathrm{C}_{\max }$ of delamanid in plasma reached $431 \mathrm{ng} / \mathrm{mL}$ at 4 hours after administration, and declined with $\mathrm{t}_{1 / 2}$ of 5.9 hours, and the $\mathrm{AUC}_{\mathrm{t}}$ and $\mathrm{AUC}_{\infty}$ were 5673 and $5697 \mathrm{ng} \cdot \mathrm{h} / \mathrm{mL}$, respectively. The lung concentrations were about three times higher than the plasma concentrations. These results suggest that delamanid penetrates into the lung after systemic administration in male mice.

Table 3. Accuracy, precision and recovery in mouse plasma and lung homogenate.

\begin{tabular}{|c|c|c|c|c|c|c|c|c|c|c|}
\hline \multirow{3}{*}{ Compound } & \multirow{3}{*}{$\begin{array}{l}\text { Spiked amount } \\
\text { (ng/mL) }\end{array}$} & \multicolumn{4}{|c|}{ Accuracy (RE\%) } & \multicolumn{4}{|c|}{ Precision (CV\%) } & \multirow{3}{*}{ 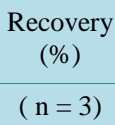 } \\
\hline & & \multicolumn{3}{|c|}{ Intra-day $(\mathrm{n}=5)$} & Inter-day ( $\mathrm{n}=15)$ & \multicolumn{3}{|c|}{ Intra-day $(\mathrm{n}=5)$} & \multirow{2}{*}{$\begin{array}{c}\text { Inter-day }(\mathrm{n}=15) \\
\text { Total }\end{array}$} & \\
\hline & & Day 1 & Day 2 & Day 3 & Total & Day 1 & Day 2 & Day 3 & & \\
\hline & & & & & Plasma & & & & & \\
\hline \multirow[t]{3}{*}{ Delamanid } & 16 & 2.8 & 2.1 & -0.6 & 1.4 & 2.3 & 2.2 & 3.6 & 3.0 & 96.5 \\
\hline & 160 & 8.3 & 10.0 & 6.0 & 8.1 & 2.3 & 7.0 & 4.3 & 4.8 & 102.0 \\
\hline & 800 & 12.0 & -4.9 & 7.2 & 4.8 & 1.8 & 6.9 & 4.1 & 8.2 & 90.8 \\
\hline IS & 200 & - & - & - & - & - & - & - & - & 101.4 \\
\hline \multicolumn{11}{|c|}{ Lung homogenate } \\
\hline \multirow[t]{3}{*}{ Delamanid } & 30 & 11.7 & 2.9 & 0.9 & 5.1 & 5.0 & 2.3 & 1.9 & 5.6 & 93.5 \\
\hline & 100 & 6.8 & 0.1 & -0.6 & 2.1 & 5.1 & 1.7 & 1.1 & 4.5 & 97.8 \\
\hline & 800 & -5.3 & -2.9 & 0.8 & -2.5 & 3.7 & 2.3 & 1.3 & 3.6 & 100.0 \\
\hline IS & 100 & - & - & - & - & - & - & - & - & 99.3 \\
\hline
\end{tabular}

Table 4. Stability results of delamanid in mouse plasma and lung homogenate.

\begin{tabular}{|c|c|c|c|c|c|}
\hline \multirow{2}{*}{ Matrix } & \multirow{2}{*}{$\begin{array}{l}\text { Spiked amount } \\
\text { (ng/mL) }\end{array}$} & \multicolumn{4}{|c|}{ Stability (\%) } \\
\hline & & Freeze-thaw stability & Short-term stability & Long-term stability & Post-preparative stability \\
\hline \multirow[t]{3}{*}{ Plasma } & & (-20 $\mathrm{C}, 3$ cycles $)$ & (ice-cold condition, 2 hours) & $\left(-20^{\circ} \mathrm{C}, 9\right.$ weeks $)$ & $\left(4^{\circ} \mathrm{C}, 24\right.$ hours $)$ \\
\hline & 16 & 102.5 & 99.6 & 90.8 & 110.7 \\
\hline & 800 & 100.6 & 101.1 & 88.8 & 100.5 \\
\hline Lung & & ( $-20^{\circ} \mathrm{C}, 2$ cycles) & (ice-cold condition, 2 hours) & $\left(-20^{\circ} \mathrm{C}, 4\right.$ weeks) & ( $4^{\circ} \mathrm{C}, 24$ hours) \\
\hline \multirow[t]{5}{*}{ homogenate } & 30 & 90.0 & 94.0 & 86.6 & 98.5 \\
\hline & 800 & 89.7 & 94.1 & 92.9 & 101.6 \\
\hline & & $\left(-20^{\circ} \mathrm{C}, 3\right.$ cycles $)$ & & $\left(-20^{\circ} \mathrm{C}, 6\right.$ weeks) & \\
\hline & 30 & 82.7 & & 80.5 & \\
\hline & 800 & 81.4 & & 90.6 & \\
\hline
\end{tabular}

Stability $(\%)=[$ measured value $(n=3)] /[$ initial value $(n=3)] \times 100$ 
Table 5. Pharmacokinetic parameters of delamanid in plasma and lung after a single oral administration at a dose of 3 $\mathrm{mg} / \mathrm{kg}$ to male mice $(\mathrm{n}=3)$.

\begin{tabular}{ccc}
\hline Parameters & Plasma & Lung \\
\hline $\mathrm{t}_{\max }($ hour $)$ & 4 & 4 \\
$\mathrm{C}_{\max }(\mathrm{ng} / \mathrm{mL})$ & 431 & 1287 \\
$\mathrm{AUC}_{\mathrm{t}}(\mathrm{ng} \cdot \mathrm{h} / \mathrm{mL})$ & 5673 & 13,768 \\
$\mathrm{AUC}_{\infty}(\mathrm{ng} \cdot \mathrm{h} / \mathrm{mL})$ & 5697 & 15,390 \\
$\mathrm{t}_{1 / 2}($ hour $)$ & 5.9 & 6.9 \\
\hline
\end{tabular}

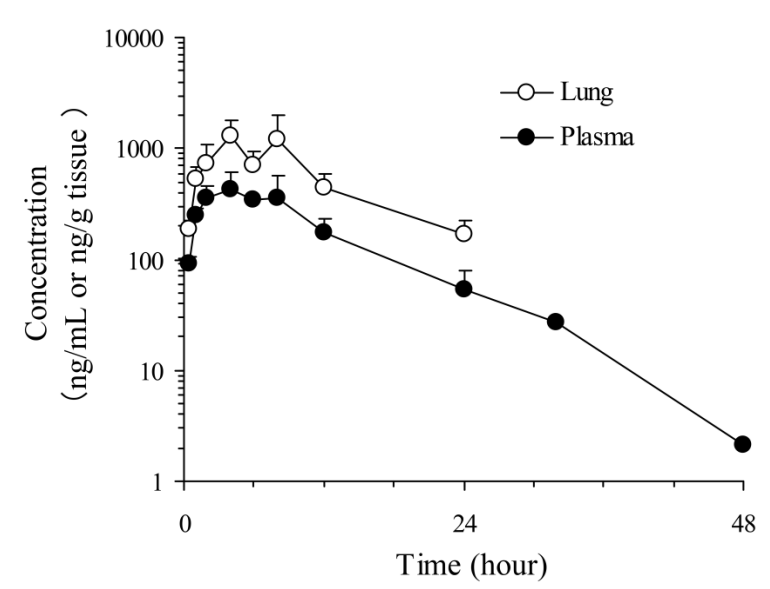

Figure 3. Concentration-time profiles of delamanid in plasma and lung after a single oral administration at a dose of 3 $\mathrm{mg} / \mathrm{kg}$ to male mice. Each point represents the mean $+\mathrm{SD}(\mathrm{n}=3)$.

\section{Conclusion}

Sensitive and selective LC-MS/MS methods using positive ion electrospray ionization have been developed and validated for the determination of delamanid in mouse plasma and lung. Sample preparation was a liquid-liquid extraction with diethyl ether for plasma, or a protein precipitation followed by liquid-liquid extraction with tertbutyl methyl ether for lung homogenate. The analytical methods have been successfully applied to a single-dose pharmacokinetic study of delamanid in male mice.

\section{References}

[1] Diacon, A.H., Dawson, R., Hanekom, M., Narunsky, K., Venter, A., Hittel, N., Geiter, L.J., Wells, C.D., Paccaly, A.J. and Donald, P.R. (2011) Early Bactericidal Activity of Delamanid (OPC-67683) in Smear-Positive Pulmonary Tuberculosis Patients. International Journal of Tuberculosis \& Lung Disease, 15, 949-954.

http://dx.doi.org/10.5588/ijtld.10.0616

[2] Gler, M.T., Skripconoka, V., Sanchez-Garavito, E., Xiao, H., Cabrera-Rivero, J.L., Vargas-Vasquez, D.E., Gao, M., Awad, M., Park, S.K., Shim, T.S., Suh, G.Y., Danilovits, M., Ogata, H., Kurve, A., Chang, J., Suzuki, K., Tupasi, T., Koh, W.J., Seaworth, B., Geiter, L.J. and Wells, C.D. (2012) Delamanid for Multidrug-Resistant Pulmonary Tuberculosis. The New England Journal of Medicine, 366, 2151-2160. http://dx.doi.org/10.1056/NEJMoa1112433

[3] Skripconoka, V., Danilovits, M., Pehme, L., Tomson, T., Skenders, G., Kummik, T., Cirule, A., Leimane, V., Kurve, A., Levina, K., Geiter, L.J., Manissero, D. and Wells, C.D. (2013) Delamanid Improves Outcomes and Reduces Mortality in Multidrug-Resistant Tuberculosis. European Respiratory Journal, 41, 1393-1400. http://dx.doi.org/10.1183/09031936.00125812

[4] Matsumoto, M., Hashizume, H., Tomishige, T., Kawasaki, M., Tsubouchi, H., Sasaki, H., Shimokawa, Y. and Komatsu, M. (2006) OPC-67683, a Nitro-Dihydro-Imidazooxazole Derivative with Promising Action against Tuberculosis in Vitro and in Mice. PLOS Medicine, 3, 2131-2144. http://dx.doi.org/10.1371/journal.pmed.0030466 
Scientific Research Publishing (SCIRP) is one of the largest Open Access journal publishers. It is currently publishing more than 200 open access, online, peer-reviewed journals covering a wide range of academic disciplines. SCIRP serves the worldwide academic communities and contributes to the progress and application of science with its publication.

Other selected journals from SCIRP are listed as below. Submit your manuscript to us via either submit@scirp.org or Online Submission Portal.
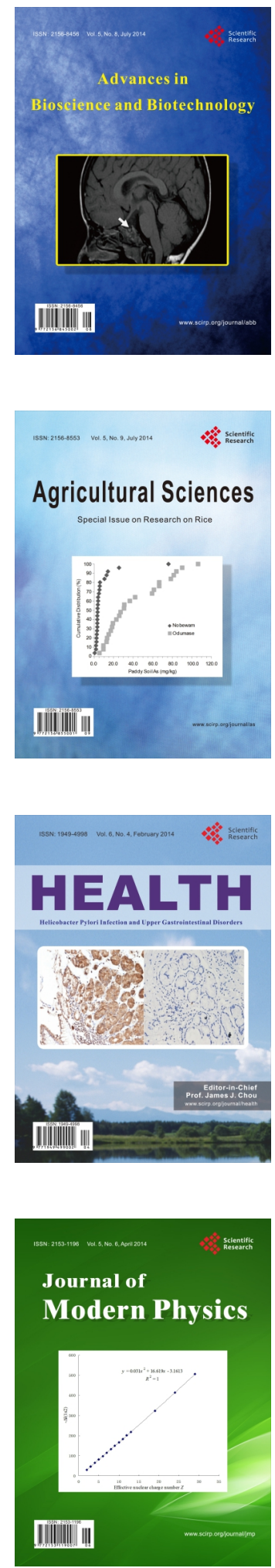
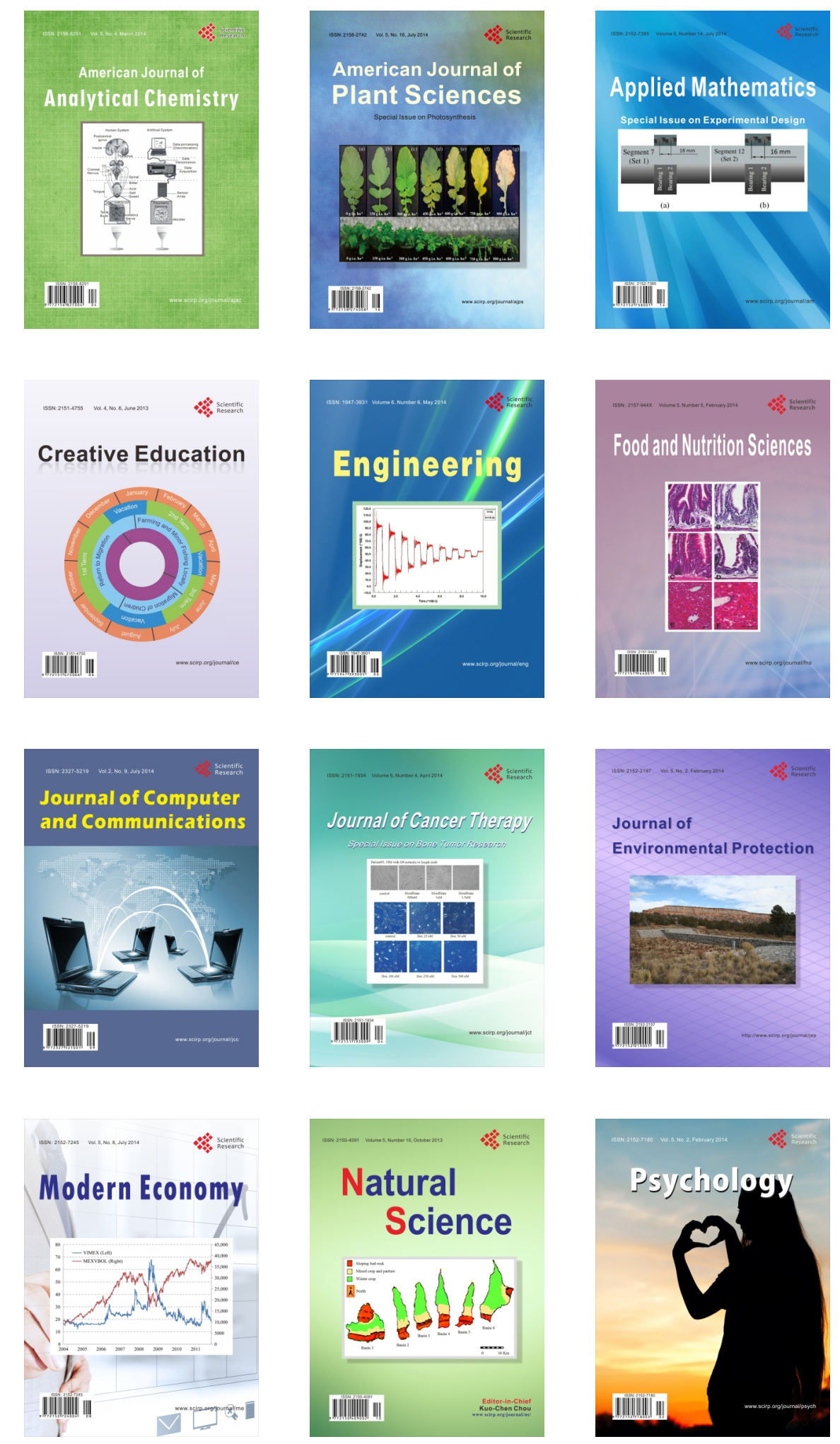